\title{
Application of Data Visualization Technology in the Process of Teaching
}

\author{
Song Yuan, Wang Fang
}

Dalian Naval Academy, 116000

\author{
Keywords: Data Visualization; Concept; Importance; Teaching Application
}

Abstract: With the progress and development of science and technology era in our country, information technology is more and more widely used in the field of education. Data visualization technology can effectively help people to carry out in-depth learning. Based on the concept and important role of data visualization technology, this paper explores its application in the field of teaching in order to provide reference for promoting teaching and scientific research in China.

\section{Introduction}

With the progress and development of our country's science and technology, the use of information technology has affected all aspects of people's lives, including the field of education. Based on the use of information technology, tremendous changes and innovations have taken place in the field of education. The modernization of teaching contents, methods, ways and tools has been realized. The corresponding network platform has also been built to carry out intelligent teaching, which effectively promotes the overall improvement of teaching quality. Therefore, how to make good use of information technology to promote the presentation of teaching content and the development of teaching process are an urgent problem for us as educators and researchers. From the current form, one of the trends of educational technology development is to make good use of data visualization technology, which can better promote students' in-depth learning and explore its application in teaching, which can effectively improve classroom efficiency and students' learning development.

\section{The Concept and Importance of Data Visualization Technology}

For the use of data visualization technology, the concrete concept and importance of data visualization must be clearly defined. At present, there are still many different concepts. Some people think that the object of data visualization is spatial data. In essence, it is an extension of computational visualization, just a more intuitive way of expression. But other researchers believe that data visualization is an evolving concept. It changes with the development of the times. It covers many aspects, such as Scientific Visualization, Knowledge Visualization and Information Visualization. But Michael Friendly and others proposed two main components of data visualization: Statistical Graphics and Thematic Cartography, mainly for the presentation of information. Friedman thinks that data visualization mainly includes seven aspects: the mind 
mapping, the news display, the data display, the connection display and the website display. Although different researchers hold different views on the concept of data visualization, this paper argues that the object of data visualization mainly includes its important participation in education and teaching. For example, the content of teaching materials, the data collected and acquired by learners in learning, and the content of knowledge learnt by students.

Data visualization can achieve effective information transmission, that is, through the intuitive transmission of the key features of data, to achieve in-depth analysis of data, so that teachers and students can effectively use the huge data generated in the process of teaching and learning, to achieve image communication between people, between people and computers, and to help people better carry out scientific research, teaching and work.

\section{Application of Data Visualization Technology in the Process of Teaching}

In daily life, the common data visualization technologies are Visual Eyes, Google Trends, Many Eyes and so on, which can be used to promote the effective use of data. In the teaching process, the application of data visualization technology can provide help and support for the development of teachers' organizing classes and students' autonomous learning.

\subsection{Teachers' Perspective}

For teachers, data visualization technology can help teachers intuitively obtain all data information about students, and teachers can use these data as the basis for the classroom organization and the teaching plan. At the same time, teachers can also get the students' behavior data from the learning management system, such as the time, place and task completion of the students' login system, and analyze the students' learning needs and time needs, so as to improve their own teaching methods, schedules and contents, and formulate personalized teaching plans that meet the students' real needs.

\subsection{Student Perspective}

In the process of training students' inquiry ability, the application of data visualization technology can effectively help students carry out data analysis and processing, and explore the law of knowledge. Or use visual knowledge model to share and communicate, find similarities and differences in communication, and promote the perfection of self-knowledge construction. At the same time, using visual modeling tools, students can intuitively present the knowledge they have absorbed, promote the development of their thinking ability, and self-reflection in the learning process. Of course, data visualization technology can also help students conduct regular self-analysis, self-reflection, and adjust their learning plan according to their own behavior data, so as to become active learners. In addition, for the data visualization processing of the learning platform, it can form a growth data record analysis which belongs only to the students themselves, and show the whole process of students' learning in an intuitive way, so as to form the growth record of students' individual.

\section{Summary}

Data visualization technology has been developed for many years, resulting in many excellent analytical data tools and software. However, there are still many shortcomings in its application in the field of education. For example, how to use data visualization technology to strengthen school management? How to mine data better? How to make knowledge more intuitive and artistic? All 
these need our research and thinking. In a word, data visualization technology is an important way for the development of teaching, which can effectively promote teachers' classroom organization, students' knowledge construction and self-evaluation.

\section{References}

[1] Liu Xia. Application of Data Visualization Technology in Classroom Teaching [J].Computer Fans, 2018 (03): 116.

[2] Zhang Jinlei, Zhang Baohui, Liu Yonggui. Application of data visualization technology in teaching [J].Modern distance education research, 2013 (06): 98-104+111.

[3] Zhang Hao, Guo Can. Trends and Classification of Data Visualization Technology Application [J]. Software Guide, 2012, 11 (05): 169-172. 